Article

\title{
Antibacterial and Antioxidant Capacities and Attenuation of Lipid Accumulation in 3T3-L1 Adipocytes by Low-Molecular-Weight Fucoidans Prepared from Compressional-Puffing-Pretreated Sargassum crassifolium
}

\author{
Chun-Yung Huang * (D), Chia-Hung Kuo ${ }^{(\mathbb{D})}$ and Chia-Hsin Lee \\ Department of Seafood Science, National Kaohsiung Marine University, No. 142, Haijhuan Rd., Nanzih District, \\ Kaohsiung 81157, Taiwan; chkuo@webmail.nkmu.edu.tw (C.-H.K.); j58675@yahoo.com.tw (C.-H.L.) \\ * Correspondence: cyhuang@webmail.nkmu.edu.tw; Tel.: +886-7-361-7141 (ext. 3606)
}

Received: 21 November 2017; Accepted: 4 January 2018; Published: 11 January 2018

\begin{abstract}
In this study, we extracted fucoidan from compressional-puffing-pretreated Sargassum crassifolium by hot water. The crude extract of fucoidan (SC) was degraded by various degradation reagents and four low-molecular-weight (LMW) fucoidans, namely SCO (degradation by hydrogen peroxide), SCA (degradation by ascorbic acid), SCOA (degradation by hydrogen peroxide + ascorbic acid), and $\mathrm{SCH}$ (degradation by hydrogen chloride) were obtained. The degradation reagents studied could effectively degrade fucoidan into LMW fucoidans, as revealed by intrinsic viscosity, agarose gel electrophoresis, and molecular weight analyses. These LMW fucoidans had higher uronic acid content and sulfate content than those of SC. It was found that SCOA exhibited antibacterial activity. All LMW fucoidans showed antioxidant activities as revealed by DPPH (2,2-diphenyl-1-picrylhydrazyl), ABTS (2,2'-azino-bis(3-ethylbenzothiazoline-6-sulfonic acid) diammonium salt), and FRAP (ferric reducing antioxidant power) methods. Biological experiments showed that SC and SCOA had relatively high activity for the reversal of $\mathrm{H}_{2} \mathrm{O}_{2}$-induced cell death in 3T3-L1 adipocytes, and SCOA showed the highest effect on attenuation of lipid accumulation in 3T3-L1 adipocytes. Therefore, for the LMW fucoidans tested, SCOA showed antibacterial activity and had a high fucose content, high sulfate content, high activity for the reversal of $\mathrm{H}_{2} \mathrm{O}_{2}$-induced cell death, and a marked effect on attenuation of lipid accumulation. It can thus be recommended as a natural and safe antibacterial and anti-adipogenic agent for food, cosmetic, and nutraceutical applications.
\end{abstract}

Keywords: 3T3-L1 cells; antibacterial; antioxidant; lipid accumulation; low-molecular-weight fucoidan; Sargassum crassifolium

\section{Introduction}

Antibacterial agents are synthetic or natural compounds that interfere with the growth and division of bacteria. A variety of studies have shown that pathogenic microorganisms in humans and various animal species have developed resistance to drugs. This drug resistance is due to the random or otherwise inappropriate usage of commercial antimicrobial agents. As such, there is an urgent need for new antibacterial agents. In addition, synthetic antibiotics have been known to induce side effects such as the appearance of resistant bacteria, skin irritation, organ damage, and immunohypersensitivity [1]. Accordingly, there is growing interest in the development of new agents, especially compounds derived from natural sources, with higher antibacterial activity but with lower or possibly even no side effects [2]. 
Oxidative stress is defined as the result of the net amount of reactive oxygen species (ROS) exceeds the antioxidant capacity, which can take place as a consequence of a general increase in ROS generation, a depression of the antioxidant systems, or both [3]. ROS in the forms of superoxide anion radical $\left(\mathrm{O}_{2}{ }^{-\bullet}\right)$, hydroxyl radical $\left({ }^{\bullet} \mathrm{OH}\right)$, hydrogen peroxide $\left(\mathrm{H}_{2} \mathrm{O}_{2}\right)$, singlet oxygen $\left({ }^{1} \mathrm{O}_{2}\right)$, and nitric oxide $\left(\mathrm{NO}^{\bullet}\right)$ are metabolic products and which may also be present in the environment [4]. The excessive production of ROS may damage cellular DNA, proteins, and lipids, leading to either alteration of biochemical compounds, or corrosion of cell membranes [5]. Antioxidants are substances that delay or prevent the oxidation of cellular oxidizable substrates. They exert their effect by scavenging ROS or preventing the generation of ROS [6]. Synthetic antioxidant compounds such as butylated hydroxytoluene (BHT) and butylated hydroxyanisole (BHA) have potent antioxidant activity and are commonly used in processed foods. However, they have been restricted because of their carcinogenicity and other toxic properties $[7,8]$. Therefore, recent research efforts have been attempted to develop naturally derived antioxidants, particularly those which possess potential nutritional and therapeutic value. Lipid accumulation in adipocytes due to impaired lipid metabolism causes adipocyte hypertrophy and accumulation of adipose tissue, which lead to obesity and metabolic syndrome $[9,10]$. In vitro and in vivo studies suggested that the reduction of lipid accumulation appeared to be associated with the mitigation of oxidative stress [11-13]. Thus, there is a need to develop antioxidants, especially from natural sources, which may efficiently attenuate adipocyte lipid accumulation.

Fucoidan represents a group of L-fucose-enriched sulfated polysaccharides extracted from brown seaweeds such as Sargassum spp. and Fucus spp. that have a worldwide distribution both in the sea and in the intertidal zone. Algal fucoidan has been characterized by a wide variety of biological activities, including antioxidant, antivirus, anti-inflammatory, antitumor, and antithrombotic and anticoagulant effects $[14,15]$. The biological activities of fucoidan are closely related to their molecular structures, which include fucose linkage, sugar type, sulfate content, and molecular weight. Among these factors, molecular weight is one of the most important factors determining the biological activities of polysaccharides [16]. High molecular weight polysaccharides may cause low solubility and processability, thereby hampering their penetration into the cell to perform a given function. In contrast, low-molecular-weight (LMW) sulfated polysaccharides show higher biological functions such as anticancer, antioxidant, and anticoagulation activities [4,17].

This study builds upon the work of our previous research [18,19]. Briefly, an oven-dried brown seaweed S. crassifolium was subjected to compressional-puffing at $18.3 \mathrm{~kg} / \mathrm{cm}^{2}$, depigmentation by $95 \%$ ethanol, and extraction of fucoidan by hot water. The high temperature and high pressure compressional-puffing process (CPP) could primarily decompose the cellular matrix of algae and increase the extraction yields of fucoidan from brown seaweed [18]. The recovered crude extract of fucoidan was utilized to investigate LMW fucoidans with respect to different degradation reagent treatments, and the recovered LMW fucoidans were examined to determine their composition, structure, molecular weight, and biological functions, including antibacterial and antioxidant capacities as well as attenuation of lipid accumulation in 3T3-L1 adipocytes. To the best of our knowledge, no such studies have been reported in the literature relating to the evaluations of the antibacterial and attenuation of lipid accumulation in 3T3-L1 adipocytes caused by LMW fucoidans obtained from compressional-puffing-pretreated S. crassifolium. In addition, we aimed to explore the potential of LMW fucoidans as natural antibacterial and anti-adipogenic agents for use in the food, cosmetic, and nutraceutical industries.

\section{Results and Discussion}

\subsection{Preparation of LMW Fucoidans}

The sample of S. crassifolium used in this study was composed of $2.36 \%$ protein, $0.98 \%$ lipid, $33.98 \%$ ash, and $62.67 \%$ carbohydrate (dry basis) [19]. Before extraction of fucoidan, the algal sample 
was pretreated by CPP with a steam pressure of $18.3 \mathrm{~kg} / \mathrm{cm}^{2}$. The CPP has been proven to effectively increase the extraction yields of fucoidan from brown seaweeds [18] and to augment the extraction yields of total phenolics and total flavonoids from pine needles [20,21]. Afterwards, we obtained one fucoidan extract (namely, SC) from the compressional-puffed algal sample by $85^{\circ} \mathrm{C}$ water extraction and ethanol precipitation (Figure 1). The extraction yields of fucoidan for compressional-puffed S. crassifolium and non-compressional-puffed S. crassifolium were $3.60 \% \pm 0.11 \%$ and $0.68 \% \pm 0.01 \%$ ( $w / w$, dry basis), respectively, which suggests that CPP could increase more than five-fold the extraction yield of fucoidan. The fucoidan extract (SC) from compressional-puffed S. crassifolium was used for further degradation experiments. Various degradation reagents including hydrogen peroxide, ascorbic acid, hydrogen peroxide + ascorbic acid, and hydrogen chloride were utilized to degrade SC, and four LMW fucoidans, namely SCO, SCA, SCOA, and SCH, were obtained, respectively. A detailed presentation of the preparation processes for SC, SCO, SCA, SCOA, and SCH is provided in Figure 1.

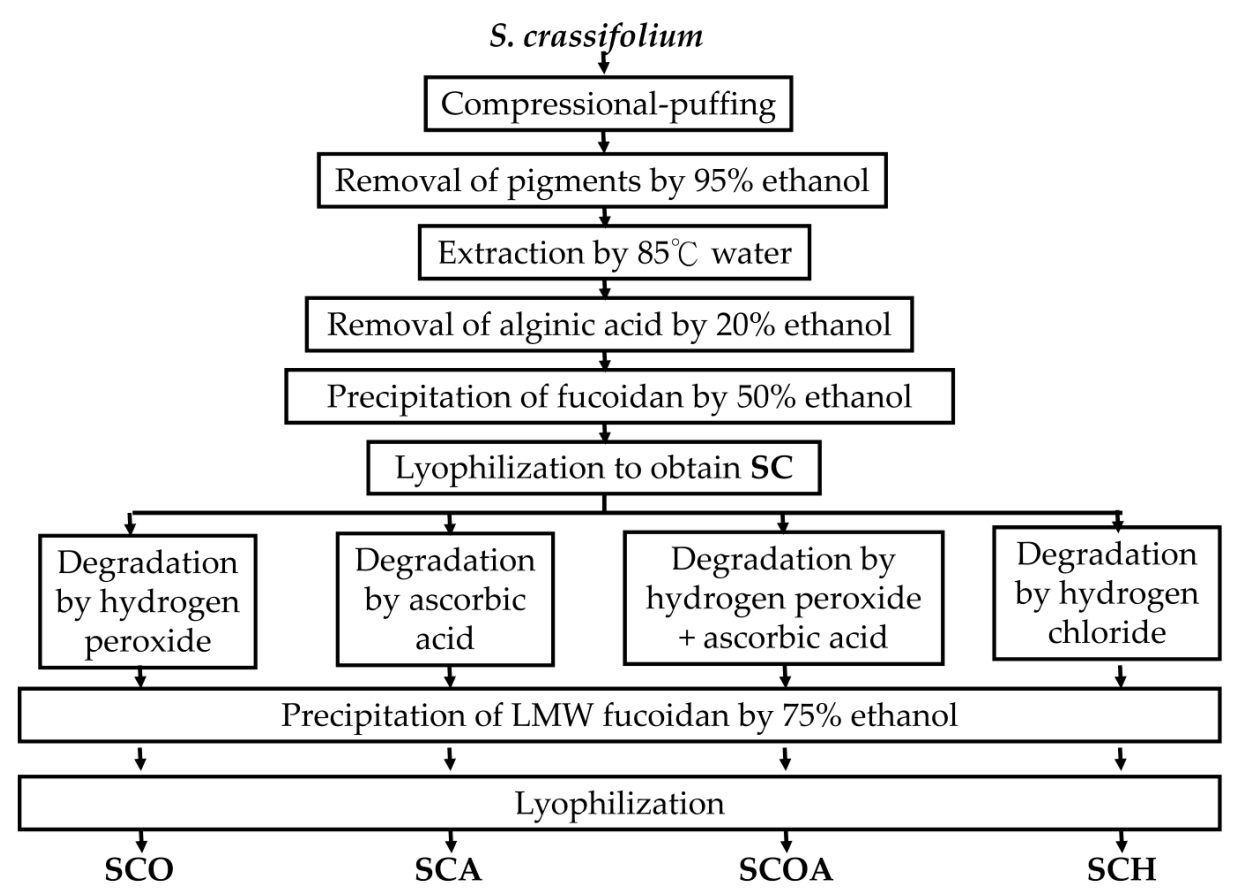

Figure 1. Flowchart of the preparation of SC (crude extract of fucoidan), SCO (degradation by hydrogen peroxide), SCA (degradation by ascorbic acid), SCOA (degradation by hydrogen peroxide + ascorbic acid), and SCH (degradation by hydrogen chloride) from Sargassum crassifolium.

\subsection{Physicochemical and Compositional Analyses of Native and LMW Fucoidans}

To evaluate whether the degradation reagents successfully degraded fucoidan, the intrinsic viscosity of polysaccharide solution was analyzed and agarose gel electrophoresis of polysaccharide was performed. Previous studies indicated that the degradation of polysaccharide solution could result in a decrease of its intrinsic viscosity [22]. Figure 2A shows the change of viscosity of polysaccharide solution under the effects of different degradation reagents. It can be seen that the viscosities of degradation reagent-treated group (SCO, SCA, SCOA, and SCH) showed an obvious decrease as compared to the non-degraded sample (SC). The results suggest that all degradation reagents can successfully degrade SC. In addition, SCOA possessed the lowest intrinsic viscosity, indicating that the degradation reagent (hydrogen peroxide + ascorbic acid) might be the most efficient for degrading fucoidan and obtaining fucoidan with lower molecular mass. Figure $2 \mathrm{~B}$ shows the electrophoretic mobility of the polysaccharide samples on agarose gel. Normally, a polysaccharide with lower molecular mass has higher mobility on agarose gel. Consistent with the result of the viscosity analysis (Figure 2A), SCOA (degraded by hydrogen peroxide + ascorbic acid) had the 
highest mobility on agarose gel, which indicates that SCOA may possess the lowest molecular mass. The molecular weights and molecular weight distributions for SC, SCO, SCA, SCOA, and $\mathrm{SCH}$ were further analyzed by high-performance liquid chromatography (HPLC) gel filtration analysis. Data presented in Table 1 revealed that the average molecular weight of extracts for $\mathrm{SC}$ was $600.23 \mathrm{kDa}$ (peak area $=100 \%$ ); for SCO were 608.41 kDa (peak area $=0.41 \%$ ), $10.80 \mathrm{kDa}$ $($ peak area $=39.61 \%)$, and $5.05 \mathrm{kDa}($ peak area $=59.98 \%)$; for SCA were $606.54 \mathrm{kDa}($ peak area $=0.90 \%)$, $14.89 \mathrm{kDa}$ (peak area $=51.64 \%$ ), and $6.87 \mathrm{kDa}$ (peak area $=47.46 \%$ ); for SCOA were $583.66 \mathrm{kDa}$ ( peak area $=0.47 \%), 13.35 \mathrm{kDa}$ (peak area $=70.55 \%$ ), and $7.62 \mathrm{kDa}$ (peak area $=28.98 \%$ ); and for SCH were $645.03 \mathrm{kDa}$ (peak area $=20.11 \%$ ) and $22.50 \mathrm{kDa}$ (peak area $=79.89 \%$ ). The data from gel filtration analysis provide evidence that, among these LMW fucoidans, SCO, SCA, and SCOA had a lower molecular weight as compared to that of SCH. For SCO, SCA, and SCOA, it was found that more than $99 \%$ of their molecular weights were less than $14.89 \mathrm{kDa}$. Moreover, SCO seemed to have the lowest molecular weight among these tested LMW fucoidans; however, the differences in the molecular weight distribution profiles among SCO, SCA, and SCOA were unremarkable. Previous studies showed that, besides molecular weight, the biological activities of fucoidan are also closely related to their compositions, such as the sugar type, monosaccharide composition, and sulfate content [15]. Thus, we measured the chemical composition and monosaccharide composition of SC, SCO, SCA, SCOA, and SCH, and the data are presented in Table 1. The total sugar contents for SCO, SCA, SCOA, and $\mathrm{SCH}$ ranged from $41.44 \% \pm 2.36 \%$ to $53.17 \% \pm 2.22 \%$ ( $w / w$, dry basis), which were similar to that of SC $(46.51 \% \pm 1.28 \%)$. The results suggest that the degradation reagents would not obviously alter the total sugar content of fucoidan. Previous studies suggested that algal polysaccharide with a higher uronic acid content may be positively related to its antioxidant activity [23]. Here, we found that the contents of uronic acid for SCO, SCA, SCOA, and SCH ranged from $23.71 \% \pm 0.31 \%$ to $29.04 \% \pm 1.01 \%$, which were significantly higher than that of SC $(14.29 \% \pm 0.62 \%)$ (Table 1$)$, indicating that the degradation process may facilitate the increase of uronic acid content in these LMW fucoidans. L-fucose was reported as the major sugar constituent in fucoidan [24]. The fucose contents for SCO, SCA, SCOA, and SCH were $24.53 \% \pm 1.89 \%, 31.64 \% \pm 1.91 \%, 33.20 \% \pm 0.54 \%$, and $30.53 \% \pm 1.89 \%$, respectively, which were in general higher than that of SC $(25.87 \% \pm 1.09 \%)$, suggesting that the degradation reagents may increase the fucose content of LMW fucoidans (Table 1). The sulfate content of fucoidan plays a critical role in the biological functions as previously noted by other investigators [25,26]. Therefore, we measured the sulfate contents for SCO, SCA, SCOA, and SCH and the percentages were $17.47 \% \pm 1.35 \%, 22.37 \% \pm 0.98 \%, 22.23 \% \pm 1.09 \%$, and $19.77 \% \pm 1.01 \%$, respectively, which were significantly higher than that of SC $(15.12 \% \pm 0.67 \%)$, suggesting that degradation reagents may also increase the sulfate content of fucoidan (Table 1). Consequently, it was expected that these LMW fucoidans (SCO, SCA, SCOA, and SCH) may exhibit higher biological activities, and thus further investigations are warranted. In addition, previous investigations indicated that crude extracts of fucoidan may contain a lot of impurities such as proteins and polyphenols, which are hard to eliminate [27]. In the present study, we found that impurities of polysaccharides caused by the presence of protein and polyphenols could be detected in SCO $(2.08+1.18=3.26, \mathrm{~g} / 100 \mathrm{~g}$, dry basis $)$, SCA $(2.02+0.79=2.81, \mathrm{~g} / 100 \mathrm{~g}$, dry basis $), \operatorname{SCOA}(2.14+0.62=2.76, \mathrm{~g} / 100 \mathrm{~g}$, dry basis $)$, and SCH $(2.30+0.86=3.16, \mathrm{~g} / 100 \mathrm{~g}$, dry basis $)$, and these values were similar to that of SC $(2.10+1.01=3.11$, $\mathrm{g} / 100 \mathrm{~g}$, dry basis), indicating that degradation reagents did not obviously affect the impurity content of LMW fucoidans. Meanwhile, constituents of neutral monosaccharide of the fucoidans were analyzed by ion chromatography. For all the tested samples, fucose, galactose, mannose, and glucuronic acid were the dominant sugar units, and the molar ratios were similar between SC and the LMW fucoidans (SCO, SCA, SCOA, and SCH). Other monosaccharides such as glucose, rhamnose, and xylose were also seen in the samples; in general, their molar ratios in LMW fucoidans (SCO, SCA, SCOA, and SCH) were less than that in SC. In addition, the Fourier transform infrared (FTIR) results of these fucoidans shown in Figure 3 suggest that the typical signals for sulfated polysaccharides were obtained. The absorption bands at 3421, 2927, and $1637 \mathrm{~cm}^{-1}$ represent the $\mathrm{O}-\mathrm{H}, \mathrm{C}-\mathrm{H}$, and $\mathrm{O}-\mathrm{C}-\mathrm{O}$ vibrations [28]. The peaks at 
$821 \mathrm{~cm}^{-1}$ and $1623 \mathrm{~cm}^{-1}$ correspond to the bending vibrations of C-O-S of sulfate and the carbonyl $\mathrm{C}=\mathrm{O}$ vibrations in uronic acid $[29,30]$. The peak at $1260 \mathrm{~cm}^{-1}$ indicates the asymmetric stretching vibration of the sulfate group $(\mathrm{S}=\mathrm{O})$ [22]. The peak at $902 \mathrm{~cm}^{-1}$ indicates $\beta$-pyranose ring vibration, and the peak at $1054 \mathrm{~cm}^{-1}$ shows C-O-H vibration $[29,31]$. Due to the similarity of the FTIR spectra in the native and LMW fucoidans, it was deduced that the position of sulfate groups and the structural aspects of sulfated polysaccharide were not significantly influenced by the degradation process. These findings were also consistent with previous investigations [28,32]. Taken together, four degradation reagents including hydrogen peroxide, ascorbic acid, hydrogen peroxide + ascorbic acid, and hydrogen chloride could effectively degrade fucoidan into LMW fucoidan as revealed by the intrinsic viscosity of polysaccharide solution, agarose gel electrophoresis of polysaccharide, and molecular weight analyses. The LMW fucoidans had higher fucose content, uronic acid content, and sulfate content than those of SC. However, the total sugar content, monosaccharide composition, and FTIR spectra between SC and LMW fucoidans were similar. Among SCO, SCA, SCOA, and SCH, the SCA and SCOA had relatively higher fucose content and higher sulfate content, and thus the biological functions of SCA and SCOA warrant further examination.
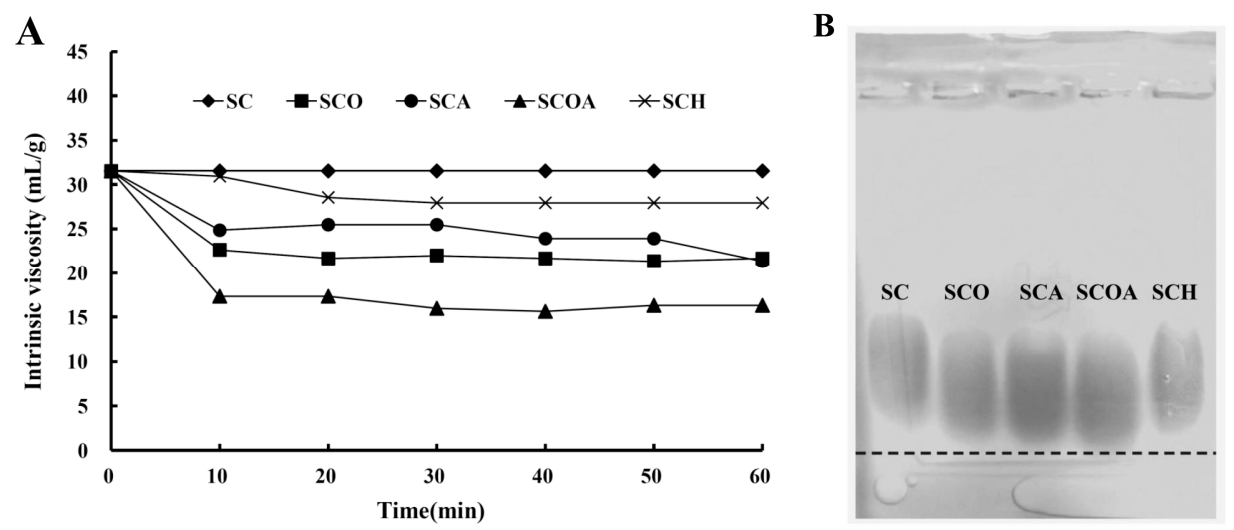

Figure 2. (A) The change of viscosity for SC, SCO, SCA, SCOA, and SCH at different time intervals; and (B) agarose gel electrophoresis analysis of SC, SCO, SCA, SCOA, and SCH.

Table 1. Composition and molecular weight analyses for SC, SCO, SCA, SCOA, and SCH.

\begin{tabular}{|c|c|c|c|c|c|}
\hline Molecular Weight (MW) & SC & SCO & SCA & SCOA & $\mathrm{SCH}$ \\
\hline Peak 1 (MW (kDa)/Peak area (\%)) & $600.23 / 100.00$ & $608.41 / 0.41$ & $606.54 / 0.90$ & $583.66 / 0.47$ & $645.03 / 20.11$ \\
\hline Peak $2(\mathrm{MW}(\mathrm{kDa}) /$ Peak area $(\%))$ & $\mathrm{ND}^{3}$ & $10.80 / 39.61$ & $14.89 / 51.64$ & $13.35 / 70.55$ & $22.50 / 79.89$ \\
\hline Peak 3 (MW (kDa)/Peak area (\%)) & ND & $5.05 / 59.98$ & $6.87 / 47.46$ & $7.62 / 28.98$ & ND \\
\hline Chemical composition & $\mathrm{SC}^{2}$ & $\mathrm{SCO}^{2}$ & $\mathrm{SCA}^{2}$ & $\mathrm{SCOA}^{2}$ & $\mathrm{SCH}^{2}$ \\
\hline Total sugar $(\%)^{1}$ & $46.51 \pm 1.28^{b}$ & $45.84 \pm 0.81^{b}$ & $41.44 \pm 2.36^{\mathrm{a}}$ & $53.17 \pm 2.22^{c}$ & $50.57 \pm 1.51^{\mathrm{c}}$ \\
\hline Uronic acid $(\%)^{1}$ & $14.29 \pm 0.62^{\mathrm{a}}$ & $27.71 \pm 1.01^{\mathrm{c}}$ & $27.38 \pm 0.94^{c}$ & $29.04 \pm 1.01^{\mathrm{c}}$ & $23.71 \pm 0.31^{b}$ \\
\hline Fucose $(\%)^{1}$ & $25.87 \pm 1.09^{\mathrm{a}}$ & $24.53 \pm 1.89^{\mathrm{a}}$ & $31.64 \pm 1.91^{b}$ & $33.20 \pm 0.54^{b}$ & $30.53 \pm 1.89^{b}$ \\
\hline Sulfate $(\%)^{1}$ & $15.12 \pm 0.67^{\mathrm{a}}$ & $17.47 \pm 1.35^{\mathrm{b}}$ & $22.37 \pm 0.98^{c}$ & $22.23 \pm 1.09^{\mathrm{c}}$ & $19.77 \pm 1.01^{b}$ \\
\hline Protein $(\%)^{1}$ & $2.10 \pm 0.04^{\mathrm{a}}$ & $2.08 \pm 0.20^{\mathrm{a}}$ & $2.02 \pm 0.01^{\mathrm{a}}$ & $2.14 \pm 0.11^{a b}$ & $2.30 \pm 0.04^{b}$ \\
\hline Polyphenols $(\%)^{1}$ & $1.01 \pm 0.13^{c}$ & $1.18 \pm 0.06^{\mathrm{d}}$ & $0.79 \pm 0.03^{b}$ & $0.62 \pm 0.08^{\mathrm{a}}$ & $0.86 \pm 0.06^{b}$ \\
\hline Monosaccharide composition (molar ratio) & SC & $\mathrm{SCO}$ & SCA & SCOA & $\mathrm{SCH}$ \\
\hline Fucose & 1 & 1 & 1 & 1 & 1 \\
\hline Galactose & 0.39 & 0.45 & 0.36 & 0.36 & 0.35 \\
\hline Mannose & 0.30 & 0.36 & 0.38 & 0.34 & 0.34 \\
\hline Glucuronic acid & 0.22 & 0.22 & 0.20 & 0.20 & 0.19 \\
\hline Glucose & 0.15 & 0.10 & 0.10 & 0.09 & 0.09 \\
\hline Rhamnose & 0.20 & 0.10 & 0.04 & 0.05 & 0.05 \\
\hline Xylose & 0.06 & 0.01 & 0.01 & ND & 0.02 \\
\hline
\end{tabular}

\footnotetext{
${ }^{1}$ Total sugars $(\%)$, uronic acid $(\%)$, fucose $(\%)$, sulfate $(\%)$, protein $(\%)$, and polyphenols $(\%)=\left(\mathrm{g} / \mathrm{g}_{\text {sample, dry basis }}\right) \times 100$;

${ }^{2}$ Values are mean $\pm \operatorname{SD}(n=3)$; values in the same row with different letters $\left({ }^{\mathrm{a}},{ }^{\mathrm{b}}, \mathrm{c}\right.$, and $\left.{ }^{\mathrm{d}}\right)$ are significantly different $(p<0.05) ;{ }^{3}$ ND: not detected.
} 


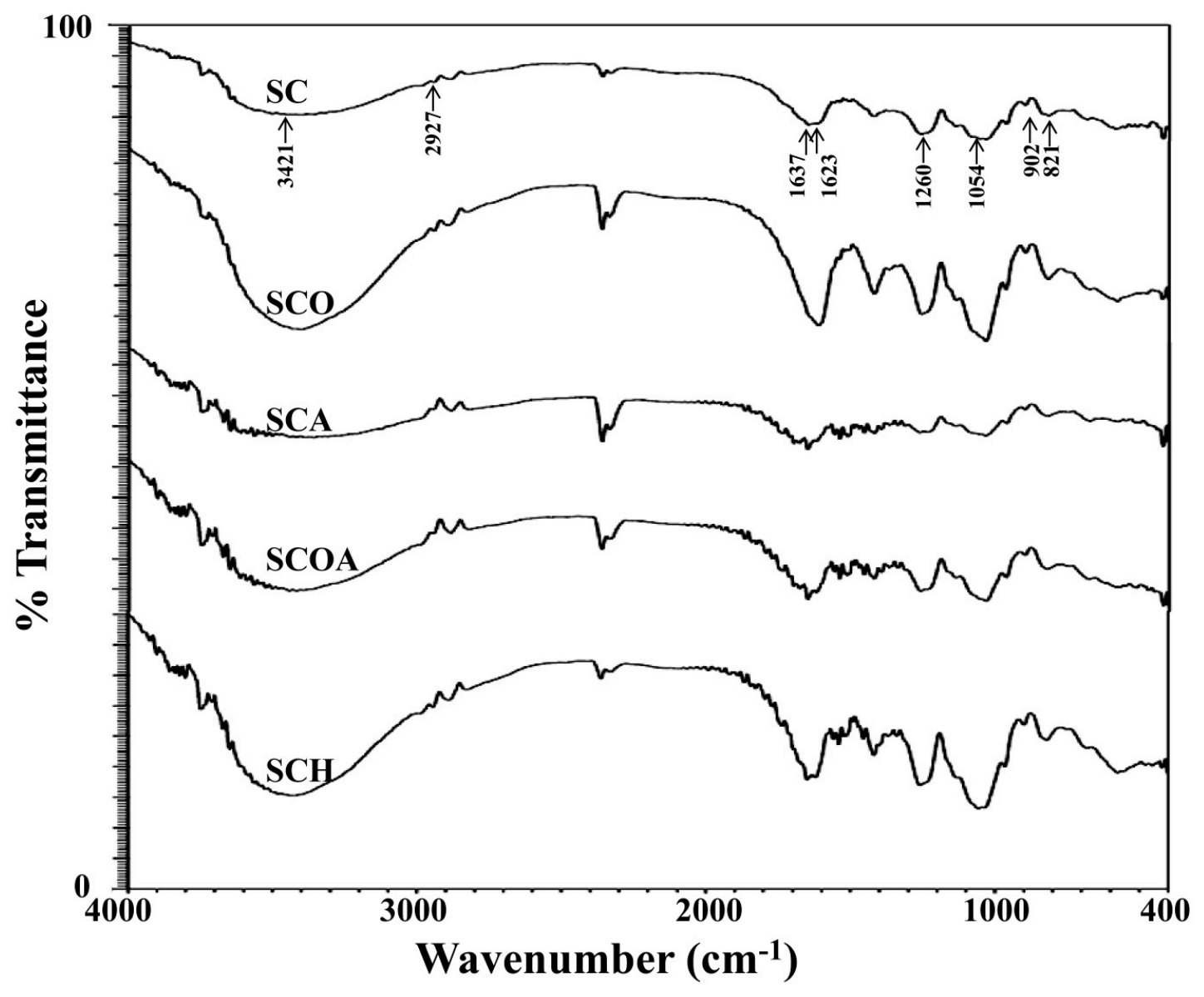

Figure 3. FTIR (Fourier Transform Infrared) spectra for SC, SCO, SCA, SCOA, and SCH.

\subsection{Antibacterial Activities of SC, SCO, SCA, SCOA, and SCH}

Previous investigations indicated that fucoidans from Laminaria japonica showed no antibacterial activity before depolymerization; however, their depolymerized products could effectively inhibit the proliferation of Escherichia coli and Staphylococcus aureus [33]. Here, we evaluated the antibacterial properties of SC, SCO, SCA, SCOA, and SCH against one Gram-negative bacterium (E. coli) and one Gram-positive bacterium (S. aureus). As seen in Figure 4, SC showed no antibacterial activity against the tested bacteria. Moreover, for the LMW fucoidans, only SCOA exhibited antibacterial activity against E. coli and S. aureus. There are two possible antibacterial pathways of sulfated polysaccharides that have been proposed in previous studies [33-35]. One pathway involves the binding of polysaccharides with the bacterial surface resulting in destruction of the cell membrane, which leads to the leakage of proteins and essential nutrients, and eventually causes the death of cells. The other pathway is thought to involve the trapping of nutrients (such as cationic minerals in the culture medium) by the negatively charged sulfated polysaccharides, leading to reduced bioavailability of the nutrients. In the present study, SCOA showed apparent antibacterial activity against Gram-negative E. coli and Gram-positive S. aureus as compared to other LMW fucoidans, and we speculate that the reason may be attributed to its ability to trap cationic minerals. However, more evidence is needed to elucidate this mechanism. In summary, SCOA exhibits antibacterial properties and has the potential for application as an effective alternative to antibiotics in the fields of food processing, agriculture, biomedicine, and other industries. 
A
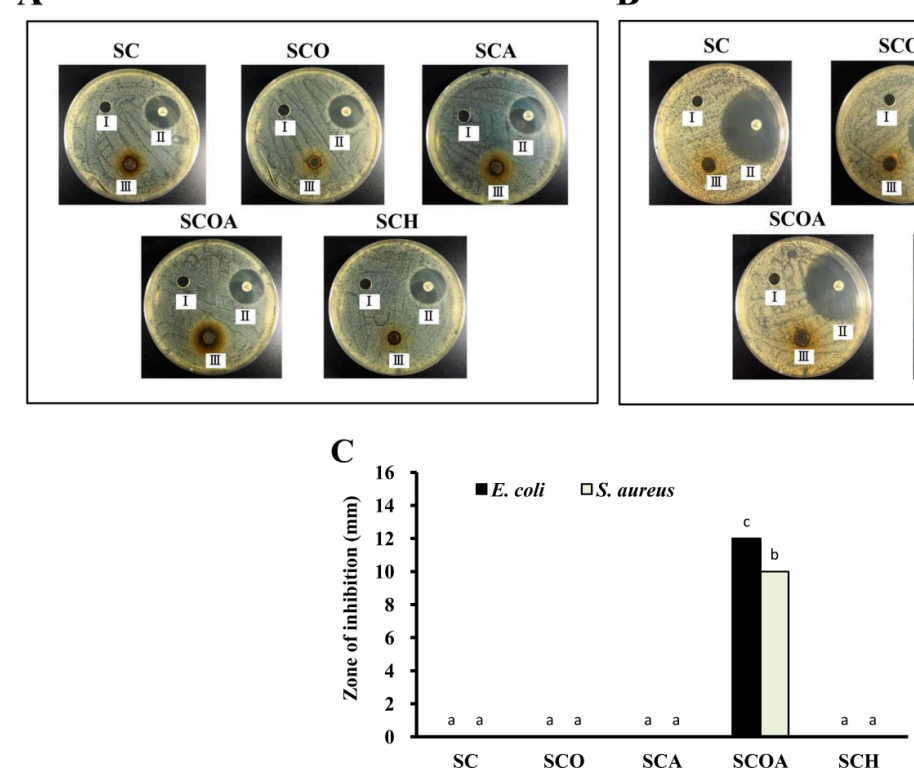

SCH
B

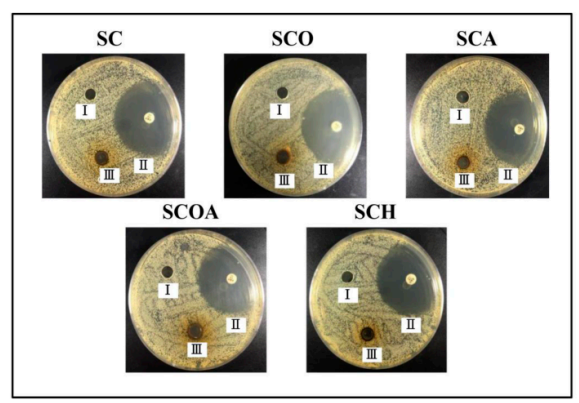

Figure 4. Zone of inhibition of: (A) Escherichia coli; and (B) Staphylococcus aureus for SC, SCO, SCA, SCOA, and SCH. I (acetate buffer), II (antibiotic), and III (polysaccharide sample) are shown in each dish; (C) The bar graph summarizes the three separate antibacterial experiments and shows the zone of inhibition according to treatments. Results are shown as mean \pm SD of three independent experiments. Different letters (in $\mathrm{a}, \mathrm{b}$, and c) mean statistically significant differences at $p<0.05$. Differences exist between columns labeled with different letters, $p<0.05$.

\subsection{Antioxidant Activities of of SC, SCO, SCA, SCOA, and SCH}

The antioxidant activities of SC, SCO, SCA, SCOA, and SCH were examined by 2,2-diphenyl-1picrylhydrazyl (DPPH), 2,2'-azino-bis(3-ethylbenzothiazoline-6-sulfonic acid) diammonium salt (ABTS), and ferric reducing antioxidant power (FRAP) analyses. DPPH is widely used to evaluate antioxidant activity in a comparatively short time [4]. Figure 5A shows the DPPH radical-scavenging properties of SC, SCO, SCA, SCOA, SCH, and vitamin C (as a reference). It can be seen that all fucoidan samples displayed DPPH radical-scavenging activity in a dose-dependent pattern. Among LMW fucoidan samples, SCA and SCOA exhibited higher DPPH radical-scavenging activity. The $\mathrm{IC}_{50}$ values (concentration of fucoidan capable of scavenging 50\% of DPPH) of the fucoidans (SC, SCO, SCA, SCOA, and SCH) on DPPH radical-scavenging activity were observed to be $2.44 \pm 0.00,3.45 \pm 0.03$, $1.81 \pm 0.09,2.43 \pm 0.07$, and $2.88 \pm 0.06 \mathrm{mg} / \mathrm{mL}$, respectively (Figure $5 \mathrm{~A}$ ), in which the potency of $\mathrm{DPPH}$ radical-scavenging activity among these fucoidans was: $\mathrm{SCA}>\mathrm{SCOA} \approx \mathrm{SC}>\mathrm{SCH}>\mathrm{SCO}$ $(p<0.05)$. Wang et al. $(2010)$ reported that the $\mathrm{IC}_{50}$ of the DPPH radical-scavenging activity for LMW fucoidan extracted from L. japonica was about $3.7 \mathrm{mg} / \mathrm{mL}$ [4], which was inferior to our result. ABTS radical decolorization assay works on a mechanism based on the decolorization of $\mathrm{ABTS}^{\bullet+}$ when it reacted with hydrogen-donating antioxidant [36]. The $\mathrm{ABTS}^{\bullet+}$ scavenging properties of SC, SCO, SCA, SCOA, SCH, and vitamin $\mathrm{C}$ (as a reference) are presented in Figure 5B. It was found that all fucoidans displayed $\mathrm{ABTS}^{\bullet+}$ scavenging activity in a dose-dependent manner. Among LMW fucoidans, the SCO and $\mathrm{SCH}$ exhibited higher $\mathrm{ABTS}^{\bullet+}$ scavenging activity. The FRAP assay measures the antioxidant effect of any substance in the reaction medium as reducing ability. The antioxidant potential of the samples was estimated from their ability to reduce TPTZ-Fe(III) complex to TPTZ-Fe(II) complex [37]. The FRAP antioxidant activity of SC, SCO, SCA, SCOA, and SCH are presented in Figure 5C. It can be seen that all fucoidan samples displayed FRAP antioxidant activity in a dose-dependent manner. Among LMW fucoidans, the SCA and SCO exhibited higher FRAP antioxidant activity. In addition, the FRAP value of SCA was observed to be $41.59 \pm 0.40 \mu \mathrm{mol}$ of vitamin C/g of fucoidan extract, which was superior to the FRAP value $(18.36 \pm 0.11 \mu \mathrm{mol}$ of vitamin $\mathrm{C} / \mathrm{g}$ of fucoidan extract) of 
fucoidan extracted from $S$. hemiphyllum performed by our laboratory. Taken together, these results confirmed that all LMW fucoidans exhibited antioxidant capacities. Lipid accumulation in adipocytes plays a critical role in the pathogenesis of obesity and related metabolic disorders [9,10], and it has also been shown to be associated with oxidative stress [11-13]. Since all LMW fucoidans exhibited antioxidant capacity, further studies are needed to fully elucidate their anti-adipogenic functions.
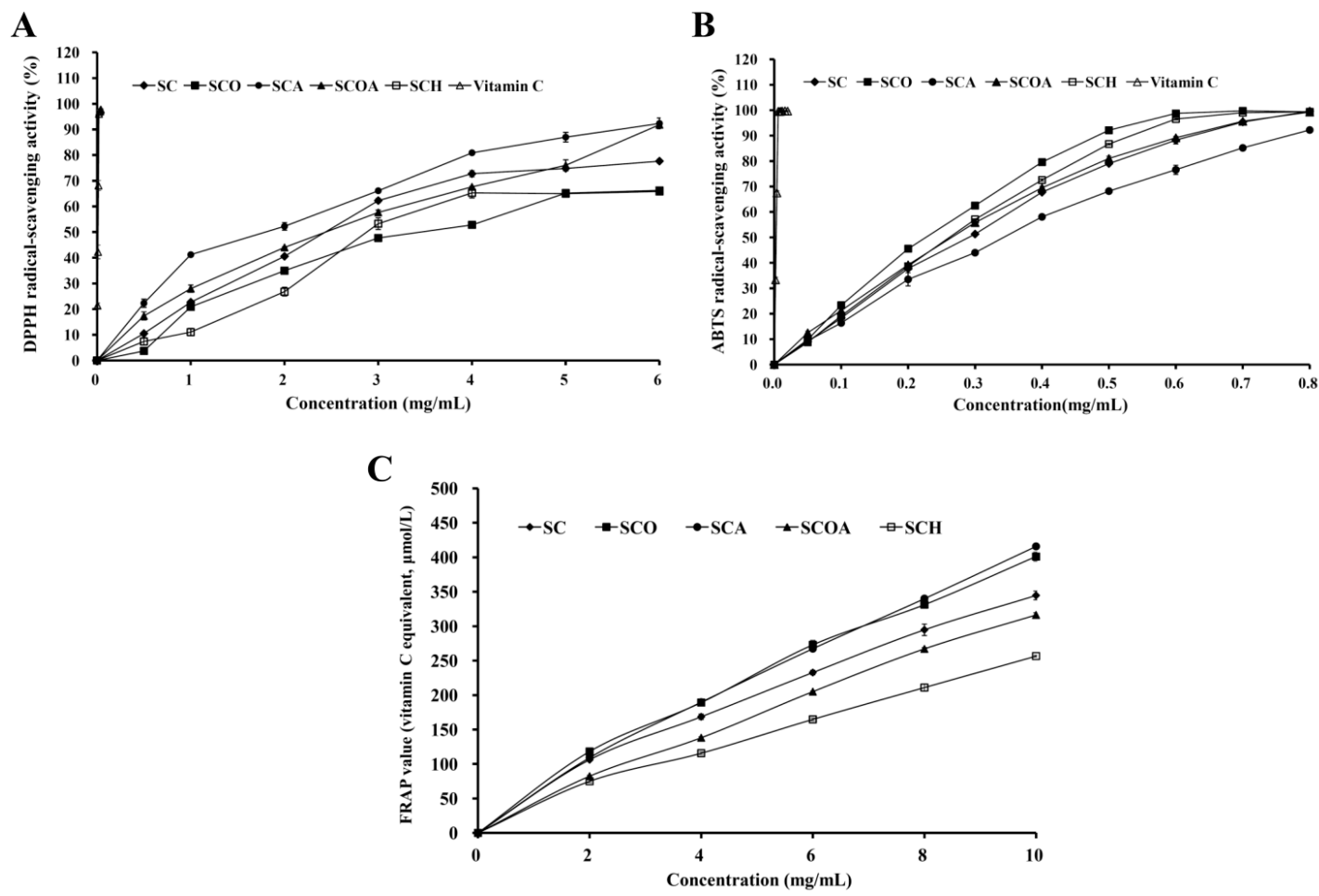

Figure 5. Antioxidant activities of SC, SCO, SCA, SCOA, and SCH: (A) DPPH radical-scavenging activity for SC, SCO, SCA, SCOA, SCH, and vitamin C; (B) ABTS radical-scavenging activity for SC, SCO, SCA, SCOA, SCH, and vitamin C; and (C) FRAP value for SC, SCO, SCA, SCOA, and SCH. Results are shown as mean $\pm \mathrm{SD}$ of three independent experiments.

\subsection{Attenuation of Lipid Accumulation in 3T3-L1 Adipocytes by SC, SCO, SCA, SCOA, and SCH}

With respect to in vitro adipocyte differentiation, 3T3-L1 is a well-known and frequently used preadipocyte cell line for studies of function and adipose tissue accumulation [38]. 3T3-L1 cells undergo adipogenic differentiation when treated with a cocktail comprising dexamethasone (DEX), methylisobutylxanthine, and insulin. After acquisition of adipocyte function and morphology, 3T3-L1 cells can accumulate microscopically detectable triglyceride droplets [39]. To evaluate the cytotoxic effect of SC, SCO, SCA, SCOA, and SCH on 3T3-L1 preadipocytes, the cells were treated with different concentrations of SC, SCO, SCA, SCOA, and SCH for $48 \mathrm{~h}$, and then the cell viability of 3T3-L1 preadipocytes was evaluated by the MTT (3-(4,5-dimethylthiazol-2-yl)-2,5-diphenyltetrazolium bromide) assay. As shown in Figure 6A, at a concentration of $100 \mu \mathrm{g} / \mathrm{mL}$, none of the studied LMW fucoidans exhibited apparent cytotoxicity to 3T3-L1 preadipocytes. Therefore, the concentration of $100 \mu \mathrm{g} / \mathrm{mL}$ for LMW fucoidans was utilized for further cellular experiments. $\mathrm{H}_{2} \mathrm{O}_{2}$ is known to be a major source of ROS and an apoptosis inducer in various cell types [19,40]. Thus, $\mathrm{H}_{2} \mathrm{O}_{2}$ was used to evaluate the protective effects of LMW fucoidans against oxidation in 3T3-L1 adipocytes. The treatment of 3T3-L1 adipocytes with $2 \mathrm{mM} \mathrm{H}_{2} \mathrm{O}_{2}$ for $24 \mathrm{~h}$ decreased the cell viability to $52.95 \% \pm 1.75 \%$ compared with the control group (Figure 6B). Moreover, pretreatment of 3T3-L1 adipocytes with SC, SCO, SCA, SCOA, or SCH at a concentration of $100 \mu \mathrm{g} / \mathrm{mL}$ followed by treatment with $2 \mathrm{mM} \mathrm{H} \mathrm{O}_{2}$ for $24 \mathrm{~h}$ attenuated $\mathrm{H}_{2} \mathrm{O}_{2}$-induced cellular cytotoxicity, and the cell 
viability values were $90.66 \% \pm 2.83 \%, 69.55 \% \pm 0.96 \%, 78.80 \% \pm 0.27 \%, 88.63 \% \pm 1.24 \%$, and $83.06 \% \pm 8.70 \%$ compared with the control group, respectively (Figure $6 \mathrm{~B}$ ). Owing to their antioxidant properties (Figure 5), LMW fucoidans could effectively reverse the $\mathrm{H}_{2} \mathrm{O}_{2}$-induced cellular cytotoxicity in 3T3-L1 adipocytes. Among the tested LMW fucoidans, SC and SCOA had the highest activity for reversal of $\mathrm{H}_{2} \mathrm{O}_{2}$-induced cell death in 3T3-L1 adipocytes. Lipid accumulation in adipocytes may cause adipocyte hypertrophy and accumulation of adipose tissue, leading to obesity and metabolic syndrome $[9,10]$. To quantify the lipid accumulation in 3T3-L1 adipocytes, an Oil Red O staining method can be used. As shown in Figure 7A,B, when 3T3-L1 cells were treated with N-acetyl cystein (NAC) (as a positive control), SC, SCO, SCA, SCOA, or SCH during the differentiation of preadipocytes to adipocytes, the lipid accumulation was decreased by $90.85 \%, 28.82 \%, 27.00 \%, 27.65 \%$, $44.14 \%$, and $32.66 \%$, respectively. These results clearly suggest that SC, SCO, SCA, SCOA, and SCH exhibited anti-adipogenic effects. Among the LMW fucoidans tested, SCOA showed the highest effect on attenuation of lipid accumulation in 3T3-L1 adipocytes. We speculate that this phenomenon may be explained by the higher fucose and sulfate contents in SCOA. However, further in vitro experiments such as oversulfation of LMW fucoidan and in vivo studies are warranted. Few studies on the inhibition of lipid accumulation in 3T3-L1 adipocytes by LMW fucoidans have been reported. Therefore, we compared the inhibitory effect of our LMW fucoidans on differentiation of 3T3-L1 preadipocytes with that of fucoidans from other investigations. The inhibitory effect of fucoidan on differentiation of 3T3-L1 preadipocytes varied considerably among different reports. Park et al. (2011) utilized a commercially available high purity fucoidan (extracted from Focus vesiculosus and obtained from Sigma) and found it could decrease the lipid accumulation of 3T3-L1 adipocytes by 16.5\% at a concentration of $100 \mu \mathrm{g} / \mathrm{mL}$ [41], which was inferior to our result for SCOA at the same concentration. However, Kim et al. (2010) utilized a commercially available high purity fucoidan (provided by Sigma) and found it could decrease the lipid accumulation of 3T3-L1 adipocytes by $50.5 \%$ at a concentration of $100 \mu \mathrm{g} / \mathrm{mL}$ [42], which was similar to the result of our SCOA at the same concentration. These findings suggest that our LMW fucoidans, especially SCOA had a similar inhibitory effect on lipid accumulation to that of highly purified fucoidan. Since highly purified fucoidan requires complicated extraction and purification processes and high production cost, our SCOA may be a good alternative for inhibition of lipid accumulation. In summary, none of the LMW fucoidans showed any obvious cytotoxicity to 3T3-L1 preadipocytes at a concentration of $100 \mu \mathrm{g} / \mathrm{mL}$. The LMW fucoidans could effectively reverse the $\mathrm{H}_{2} \mathrm{O}_{2}$-induced cellular cytotoxicity of 3T3-L1 adipocytes. In addition, all LMW fucoidans exhibited an anti-adipogenic effect as revealed by the attenuation of lipid accumulation during differentiation of 3T3-L1 preadipocytes. Among the LMW fucoidans tested, SCOA showed the highest effect on attenuation of lipid accumulation, and thus it may have potential as a natural and safe anti-adipogenic agent for food and nutraceutical applications.

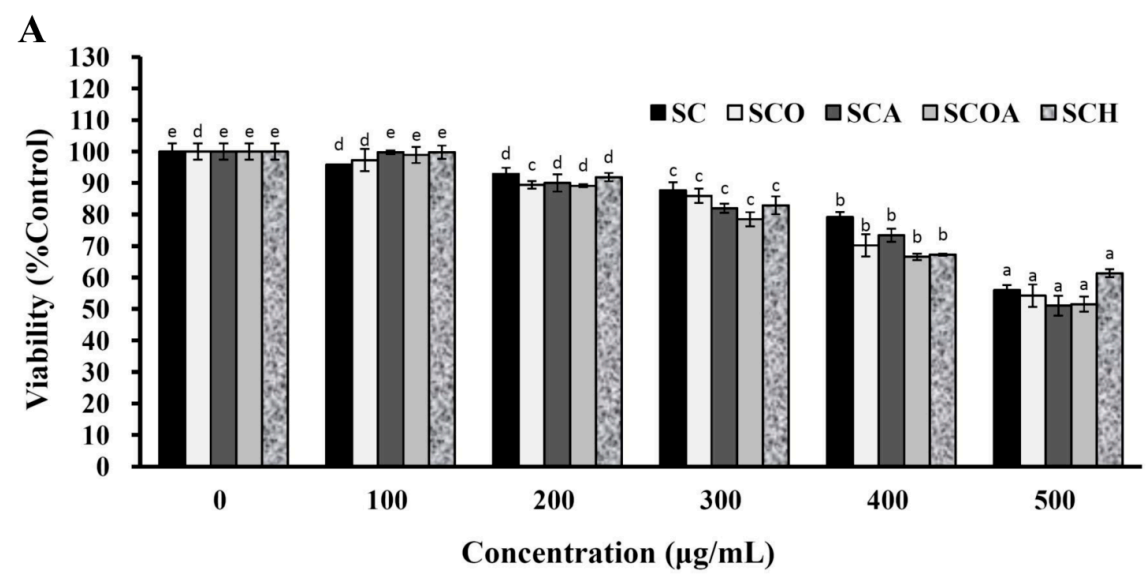

Figure 6. Cont. 


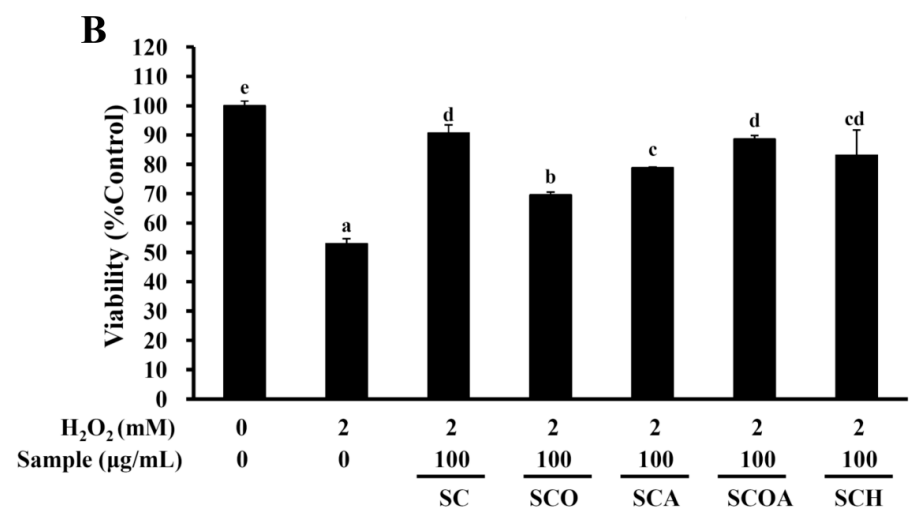

Figure 6. Effects of SC, SCO, SCA, SCOA, and SCH and $\mathrm{H}_{2} \mathrm{O}_{2}$ treatment with or without SC, SCO, SCA, SCOA, and SCH pretreatment on cell viability of 3T3-L1 cells: (A) 3T3-L1 preadipocytes were treated with SC, SCO, SCA, SCOA, or SCH (0-500 $\mu \mathrm{g} / \mathrm{mL})$ for $48 \mathrm{~h}$, and cell viability was assessed. Results are shown as mean $\pm \mathrm{SD}$ of three independent experiments. In each group of columns related to each concentration of sample, differences exist between columns labeled with different letters, $p<0.05$; (B) 3T3-L1 adipocytes were pretreated with $100 \mu \mathrm{g} / \mathrm{mL}$ SC, SCO, SCA, SCOA, or SCH, followed by treatment with $2 \mathrm{mM} \mathrm{H}_{2} \mathrm{O}_{2}$ for $24 \mathrm{~h}$, and cell viability was assessed. Results are shown as mean $\pm \mathrm{SD}$ of three independent experiments. Different letters (in a, b, c, d, and e) mean statistically significant differences at $p<0.05$. In each group of columns related to each treatment, differences exist between columns labeled with different letters, $p<0.05$.
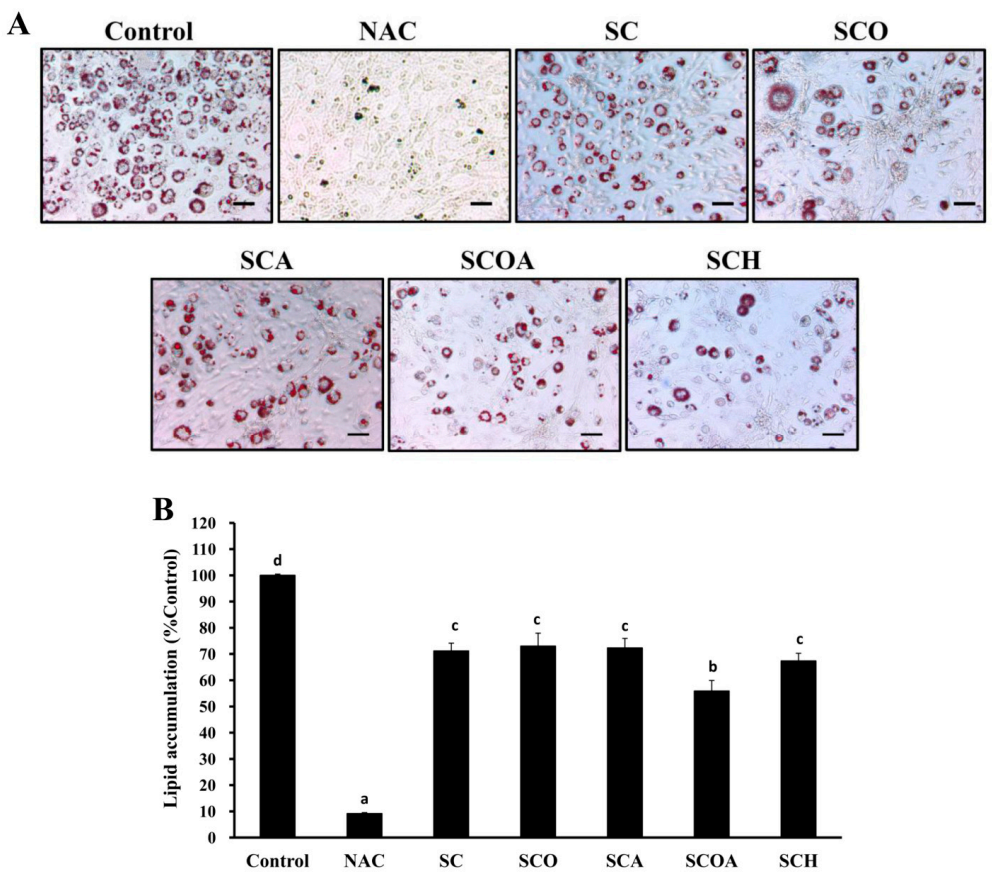

Figure 7. Effects of SC, SCO, SCA, SCOA, SCH, and NAC on lipid accumulation during the differentiation of 3T3-L1 preadipocytes: (A) 3T3-L1 preadipocytes were treated without or with SC, SCO, SCA, SCOA, SCH $(100 \mu \mathrm{g} / \mathrm{mL})$ and NAC (10 mM), and differentiating 3T3-L1 cells with visible lipid accumulation were examined on Day 8 by Oil Red O staining. The scale bar $(100 \mu \mathrm{m})$ is shown in each graph; (B) The bar graph summarizes the three separate experiments and shows the percentage of lipid accumulation in 3T3-L1 adipocytes according to treatments. Results are shown as mean \pm SD of three independent experiments. Different letters (in a, b, c, and d) mean statistically significant differences at $p<0.05$. Differences exist between columns labeled with different letters, $p<0.05$. 


\section{Materials and Methods}

\subsection{Materials and Chemicals}

A sample of S. crassifolium (SC) was collected from Pingtung, Taiwan and then washed with fresh water, oven-dried at $50{ }^{\circ} \mathrm{C}$, and kept in plastic bags at $4{ }^{\circ} \mathrm{C}$ until further experiments. L-fucose, L-rhamnose, D-glucose, D-glucuronic acid, D-galactose, D-mannose, D-xylose, D-galacturonic acid, gallic acid, sodium carbonate, DPPH, ABTS, 2,4,6-tripyridyl-s-triazine (TPTZ), 3-isobutyl-1-methylxanthine (IBMX), ammonium acetate, Bradford reagent, bovine serum albumin (BSA), DEX, insulin, NAC, nitroblue tetrazolium (NBT), Oil Red O, thioglycolic acid solution, toluidine blue, and dimethyl sulfoxide (DMSO) were purchased from Sigma-Aldrich (St. Louis, MO, USA). Potassium bromide (KBr) was purchased from Merck (Darmstadt, Germany). 2,2,2-Trifluoroacetic acid (TFA) was obtained from Panreac (Barcelona, Spain). Peptone, TSA, and TSB were purchased from BD Biosciences (San Jose, CA, USA). DMEM, trypsin/EDTA, fetal calf serum (FCS), penicillin, and streptomycin were purchased from Gibco Laboratories (Grand Island, NY, USA). All other reagents were of analytical grade or the best grade available.

\subsection{Compressional-Puffing Procedure}

The dried algal sample was puffed according to our previously described procedure [18] with slight modification. In brief, the algal sample was automatically put into the chamber and the puffing conditions were set with temperature at $220^{\circ} \mathrm{C}$. After $\mathrm{CPP}$, the algal sample was ground into fine particles and stored at $4{ }^{\circ} \mathrm{C}$ for further extraction experiments.

\subsection{Water Extraction Procedure}

We followed the methods of Yang et al. (2017) [19]. In brief, the compressional-puffed algal sample was mixed with $95 \%$ ethanol $(w / v=1: 10)$, shaken for $4 \mathrm{~h}$ at room temperature to remove pigments, proteins and lipid, and then centrifuged at $970 \times g$ for $10 \mathrm{~min}$. The residue was collected, mixed with double-distilled water $(w / v=1: 10)$ and placed in a water-bath kept at $85{ }^{\circ} \mathrm{C}$ for $1 \mathrm{~h}$ with shaking $(120 \mathrm{rpm})$ to extract the polysaccharides. The mixture was centrifuged at $3870 \times g$ for $10 \mathrm{~min}$ and the supernatant was collected. Ethanol (95\%) was added into the supernatant to give a final ethanol concentration of $20 \%$ in order to precipitate alginic acid. The mixture was centrifugated at $9170 \times g$ for $30 \mathrm{~min}$, the supernatant was collected, and 95\% ethanol was added until a final ethanol concentration of $50 \%$ was reached in order to obtain fucoidan precipitate. The ethanol-precipitated fucoidan was then recovered by centrifugation at $9170 \times g$ for $30 \mathrm{~min}$ and lyophilized. Extraction yield was calculated using the following equation:

$$
\text { Extraction yield }(\%)=\left(g_{\mathrm{A}} / g_{\mathrm{B}}\right) \times 100
$$

where $g_{\mathrm{A}}$ represents the weight of the extracted solid on a dry basis, and $g_{\mathrm{B}}$ is the weight of the sample on a dry basis.

\subsection{Degradation Procedure}

A solution of native fucoidan sample $(0.1 \mathrm{~g})$ in double distilled water $(10 \mathrm{~mL})$ was added in $10 \mathrm{mM} \mathrm{H}_{2} \mathrm{O}_{2}, 10 \mathrm{mM}$ ascorbic acid, a mixed solution of $10 \mathrm{mM} \mathrm{H}_{2} \mathrm{O}_{2}$ and $10 \mathrm{mM}$ ascorbic acid, or $0.1 \mathrm{~N} \mathrm{HCl}$, respectively. For $\mathrm{HCl}$ treatment, the $\mathrm{pH}$ of reaction solution was adjusted to 2.0 by $0.1 \mathrm{~N} \mathrm{NaOH}$ at the start of reaction. Then the solution was stirred to start the degradation reaction. The time of reaction was $1 \mathrm{~h}$. For $\mathrm{HCl}$ treatment, the $\mathrm{pH}$ of reaction solution was adjusted to 7.0 by $0.1 \mathrm{~N} \mathrm{NaOH}$ at the end of reaction. After the reaction, the LMW fucoidan was precipitated by adding $75 \%$ ethanol and the ethanol-precipitated LMW fucoidan was then recovered by centrifugation at $9170 \times g$ for $30 \mathrm{~min}$ and lyophilized. 


\subsection{Chemical Methods}

The phenol-sulfuric acid colorimetric method was used to determine the total sugar content, and D-galactose was used as the standard [43]. The fucose content was determined by the method of Gibbons [44], and L-fucose was used as the standard. Uronic acids were estimated by the colorimetric method using D-galacturonic acid as the standard [45]. Protein was quantified by the Bradford method using BSA as the standard [46]. Polyphenols were analyzed by the Folin-Ciocalteu method and gallic acid was used as the standard [47]. Sulfate content of polysaccharide was determined by first hydrolyzing the polysaccharide with $1 \mathrm{~N} \mathrm{HCl}$ solution for $5 \mathrm{~h}$ at $105^{\circ} \mathrm{C}$. The hydrolysate was then quantified based on the percentage of sulfate composition using Dionex ICS-1500 Ion Chromatography (Sunnyvale, CA, USA) with an IonPac AS9-HC column $(4 \times 250 \mathrm{~mm})$ at a flow rate of $1 \mathrm{~mL} / \mathrm{min}$ at $30{ }^{\circ} \mathrm{C}$ with conductometric detection. The eluent was $9 \mathrm{mM} \mathrm{Na}_{2} \mathrm{CO}_{3}$, and $\mathrm{K}_{2} \mathrm{SO}_{4}$ was utilized as the standard.

\subsection{Analysis of Monosaccharide Composition}

The monosaccharide composition of polysaccharide was analyzed according a previously described method [18], using L-fucose, D-xylose, D-galactose, D-glucose, D-glucuronic acid, L-rhamnose, and D-mannose as the standards.

\subsection{Intrinsic Viscosity Analysis}

The intrinsic viscosity of polysaccharide solution was determined in an Ubbelohde viscosimeter at $25^{\circ} \mathrm{C}$. The result of intrinsic viscosity $\left(\eta_{\mathrm{r}}\right)$ was calculated using the following equation:

$$
\eta_{\mathrm{r}}=\left(\ln \mathrm{t} / \mathrm{t}_{0}\right) / \mathrm{c}
$$

where $\mathrm{t}$ is the solution flow time (s), $\mathrm{t}_{0}$ is the solvent flow time (s), and $\mathrm{c}$ is the concentration of solution $(\mathrm{g} / \mathrm{mL})[22]$.

\subsection{Agarose Gel Electrophoresis}

About $5 \mu \mathrm{g}$ of polysaccharide sample was applied to a $0.5 \%$ agarose gel in $0.05 \mathrm{M} 1$,3-diaminopropane/ acetate buffer ( $\mathrm{pH} 9.0$ ) for $1 \mathrm{~h}$ at $110 \mathrm{~V}$. The polysaccharide in the gel was fixed with $0.1 \% \mathrm{~N}$-cetyl- $N$, $\mathrm{N}, \mathrm{N}$-trimethylammonium bromide in water. Thereafter, polysaccharides were stained using $0.1 \%$ toluidine blue in acetic acid/ethanol/water $(0.1: 5: 5, v / v / v)$ [48].

\subsection{Fourier Transform Infrared (FTIR) Spectroscopy}

The FTIR analysis was performed according to the method of Huang [49]. In brief, polysaccharide and $\operatorname{KBr}(w / w, 1: 50)$ were mixed and ground evenly until particles measured less than $2.5 \mu \mathrm{m}$ in size. The transparent $\mathrm{KBr}$ pellets were made at $500 \mathrm{~kg} / \mathrm{cm}^{2}$ under vacuum. The FTIR spectra were obtained using a FT-730 spectrometer (Horiba, Kyoto, Japan), and the absorbance was read between 400 and $4000 \mathrm{~cm}^{-1}$. Pellet of $\mathrm{KBr}$ alone was used as a background.

\subsection{Molecular Weight Analysis}

The molecular weight analysis of the polysaccharides was conducted according to the method of Yang [19]. The standards used to calibrate the column were various dextrans with different molecular weights $(1,5,12,50,150$, and $670 \mathrm{kDa})$, which were obtained from Sigma-Aldrich (Sigma-Aldrich, St. Louis, MO, USA)

\subsection{Zone of Inhibition}

Two bacteria were tested for antibacterial activity of polysaccharides. These included one Gram-negative bacterium (E. coli BCRC 10675) and one Gram-positive bacterium (S. aureus BCRC 
10780), which were obtained from the Culture Collection and Research Center of the Food Industry Research and Development Institute, Hsinchu, Taiwan. Antibacterial activity was measured using a previously described method [50]. In brief, E. coli and S. aureus were grown in tryptic soy broth (TSB) medium (Difco Laboratories, Detroit, MI, USA) for $24 \mathrm{~h}$ at $30^{\circ} \mathrm{C}$, and $0.1 \mathrm{~mL}$ of each culture of bacteria at the proper cell density was spread on Tryptic soy agar (TSA, Difco Laboratories, Detroit, MI, USA) plate surfaces. A volume measuring $100 \mu \mathrm{L}$ of each polysaccharide sample $(400 \mathrm{mg} / \mathrm{mL}$ in $0.05 \mathrm{M}$ acetate buffer, $\mathrm{pH}$ 6.0) or $0.05 \mathrm{M}$ acetate buffer (as a negative control) was delivered separately into wells ( $8 \mathrm{~mm}$ in diameter). Positive control paper disc was prepared by impregnating it with a volume measuring $50 \mu \mathrm{L}$ of $10 \%(v / v)$ Antibiotic-Antimycotic Solution (containing 10,000 units/mL penicillin, $10 \mathrm{mg} / \mathrm{mL}$ streptomycin, and $25 \mu \mathrm{g} / \mathrm{mL}$ amphotericin) (Corning, Corning, NY, USA). The plates were incubated at $35^{\circ} \mathrm{C}$ for $24 \mathrm{~h}$. After $24 \mathrm{~h}$, the antibacterial activity of polysaccharides against the test bacteria was observed to determine whether any zones of microbial growth inhibition had developed, which would indicate the occurrence of antimicrobial action, and any such activity was expressed in terms of average diameter of the zone of inhibition measured in millimeters.

\subsection{DPPH Radical Scavenging Activity}

The DPPH radical scavenging activity was determined according to a method described elsewhere [19]. Briefly, $50 \mu \mathrm{L}$ of sample was added to $150 \mu \mathrm{L} 0.1 \mathrm{mM}$ freshly prepared DPPH solution (in methanol). The mixture was shaken vigorously for $1 \mathrm{~min}$, left to stand for $30 \mathrm{~min}$ in the dark at room temperature, and the absorbance of all sample solutions was measured at $517 \mathrm{~nm}$ using an ELISA reader (PowerWave 340, Bio-Tek Instruments, Winooski, VT, USA). The radical-scavenging activity was calculated using the following equation:

$$
\mathrm{DPPH}_{\text {radical-scavenging }}(\%)=\left[1-\frac{\mathrm{A}_{\text {sample }}}{\mathrm{A}_{\text {control }}}\right] \times 100
$$

where $\mathrm{A}_{\text {sample }}$ is the absorbance of the methanol solution of DPPH with tested samples, and $\mathrm{A}_{\text {control }}$ represents the absorbance of the methanol solution of DPPH without the sample.

\subsection{ABTS Radical Cation Scavenging Activity}

The scavenging activity of the samples against ABTS radical cation was measured according to a method described elsewhere [19]. In brief, the ABTS ${ }^{\bullet+}$ solution was prepared by reacting $5 \mathrm{~mL}$ of ABTS solution $(7 \mathrm{mM})$ with of $88 \mu \mathrm{L}$ of potassium persulfate $(140 \mathrm{mM})$, and the mixture was kept in the dark at room temperature for $16 \mathrm{~h}$. The solution was diluted with $95 \%$ ethanol to obtain an absorbance of $0.70 \pm 0.05$ at $734 \mathrm{~nm}$. To start the assay, $100 \mu \mathrm{L}$ diluted $\mathrm{ABTS}^{\bullet+}$ solution was mixed with $100 \mu \mathrm{L}$ of various sample solutions. The mixture was allowed to react at room temperature for $6 \mathrm{~min}$, and the absorbance of all sample solutions at $734 \mathrm{~nm}$ was measured using an ELISA reader (PowerWave 340, Bio-Tek Instruments, Winooski, VT, USA). The blank was prepared in the same manner, except that distilled water was used instead of the sample. The activity of scavenging ABTS ${ }^{\bullet+}$ was calculated according to the following equation:

$$
\operatorname{ABTS}_{\text {cation radical-scavenging }}(\%)=\left[1-\frac{\mathrm{A}_{\text {sample }}}{\mathrm{A}_{\text {control }}}\right] \times 100
$$

where $\mathrm{A}_{\text {sample }}$ is the absorbance of ABTS with tested samples, and $\mathrm{A}_{\text {control }}$ represents the absorbance of ABTS without the sample.

\subsection{FRAP Assay}

The FRAP assay was performed according to the protocol proposed by Benzie and Strain [51] Briefly, the FRAP solution was prepared by adjusting $10 \mathrm{~mL}$ of acetate buffer $(300 \mathrm{mM})$ to $\mathrm{pH} 3.6$ via the addition of acetic acid. It was then mixed with $1 \mathrm{~mL}$ of ferric chloride hexahydrate $(20 \mathrm{mM})$ 
dissolved in distilled water and $1 \mathrm{~mL}$ of TPTZ $(10 \mathrm{mM})$ dissolved in $\mathrm{HCl}(40 \mathrm{mM})$. A volume measuring $50 \mu \mathrm{L}$ of the test sample dissolved at different concentrations was prepared. Freshly prepared FRAP solution $(450 \mu \mathrm{L})$ warmed at $37^{\circ} \mathrm{C}$ was added to the sample and allowed to react for 30 min under dark conditions, while the same volume of acetate buffer was utilized as the blank. The absorbance at $593 \mathrm{~nm}$ was monitored by an ELISA reader (PowerWave 340, Bio-Tek Instruments, Winooski, VT, USA). Vitamin C was used as a standard and FRAP values were expressed as micromole vitamin C equivalents per gram of sample on a dry basis ( $\mu \mathrm{mol}$ vitamin $\mathrm{C} / \mathrm{g}$ sample, dry basis).

\subsection{Adipocyte Cell Culture}

Mouse 3T3-L1 (ATCC ${ }^{\circledR}$ CCL-92.1 $1^{\mathrm{TM}}$ ) cells were purchased from the Food Industry Research and Development Institute, Hsinchu, Taiwan which had originally obtained them from the American Type Culture Collection (ATCC) (Rockville, CT, USA). Cultured 3T3-L1 cells were maintained in DMEM containing $10 \%$ FCS. To induce differentiation, two-day post-confluent preadipocytes were cultured in DMEM containing $10 \%$ FCS, $10 \mu \mathrm{g} / \mathrm{mL}$ insulin, $1 \mu \mathrm{M}$ DEX, and $0.5 \mathrm{mM}$ IBMX for three days. Cells were then cultured in DMEM supplemented with $10 \% \mathrm{FCS}$ and $10 \mu \mathrm{g} / \mathrm{mL}$ insulin for another two days, after which cells were fed every other day with DMEM containing $10 \% \mathrm{FCS}$ at $37^{\circ} \mathrm{C}$ and $5 \% \mathrm{CO}_{2}$, and thus the total duration of the differentiation process was 8 days [52].

\subsection{Cell Viability Test}

Cell viability was measured by quantitative colorimetric MTT assay [53]. Briefly, 3T3-L1 cells $\left(1 \times 10^{6} / \mathrm{mL}\right.$ in a 96-well plate) were plated with culture medium and incubated for $48 \mathrm{~h}$ at $37^{\circ} \mathrm{C}$, with $5 \% \mathrm{CO}_{2}$ in a humidified atmosphere. The cells were then incubated with test compounds at various concentrations for various times. The reaction was stopped by removing the treatment media, adding MTT reagent $(1 \mathrm{mg} / \mathrm{mL})$, and then allowing the reagent to react at $37^{\circ} \mathrm{C}$ in $5 \% \mathrm{CO}_{2}$ for $4 \mathrm{~h}$. MTT was removed, and cells were lysed with DMSO. The absorbance at $570 \mathrm{~nm}$ was measured using an ELISA reader (PowerWave 340, Bio-Tek Instruments, Winooski, VT, USA). The cell viability (\%) was calculated using the following equation:

$$
\text { Cell viability }(\%)=\left(\frac{T}{\mathrm{C}}\right) \times 100
$$

where $\mathrm{T}$ is the absorbance in the test, and $\mathrm{C}$ is the absorbance for the control.

\subsection{Lipid Accumulation}

Intercellular lipid accumulation was measured by Oil Red O staining during adipocyte differentiation [54]. In brief, treated mature adipocytes were washed with PBS and fixed for $1 \mathrm{~h}$ with $10 \%$ formalin $(v / v$ in PBS). The Oil Red O solution was prepared by dissolving $0.5 \mathrm{~g}$ of Oil Red O powder in $100 \mathrm{~mL}$ of $100 \%$ isopropanol and diluted to a final volume of $167 \mathrm{~mL}$ with $\mathrm{H}_{2} \mathrm{O}$. Each well was stained with dye solution for $15 \mathrm{~min}$, after which the cells were washed with $\mathrm{H}_{2} \mathrm{O}$ four times and allowed to air-dry. Stained cells were visualized by light microscopy and photographed. The Oil Red O dye was eluted from the lipid droplets by adding 100\% isopropanol for $5 \mathrm{~min}$. The resulting eluent was analyzed by an ELISA reader (PowerWave 340, Bio-Tek Instruments, Winooski, VT, USA) at a wavelength of $490 \mathrm{~nm}$. The lipid accumulation (\%) was calculated using the following equation:

$$
\text { Lipid accumulation }(\%)=\left(\frac{A_{\text {treatment }}-A_{\text {blank }}}{A_{\text {control }}-A_{\text {blank }}}\right) \times 100
$$

where $A_{\text {treatment }}$ is the absorbance for the cells and test samples, $A_{\text {control }}$ is the absorbance for the cells only, and $A_{b l a n k}$ is the absorbance for the medium only. 


\subsection{Statistical Analysis}

Results are presented as means \pm standard deviation (SD) of three independent experiments. Data were analyzed using the Statistical Package for the Social Sciences (SPSS). The results obtained were analyzed using one-way analysis of variance (ANOVA), followed by Duncan's Multiple Range tests. Data were considered statistically different at $p<0.05$.

\section{Conclusions}

In this paper, we extracted fucoidan from compressional-puffed S. crassifolium by hot water. Various degradation reagents were used to degrade the crude extract of fucoidan (SC) and four LMW fucoidans, SCO, SCA, SCOA, and SCH, were obtained. The LMW fucoidans had higher uronic acid content and sulfate content than those of SC. All LMW fucoidans showed antioxidant activities, as revealed by the DPPH, ABTS, and FRAP methods. It was found that only SCOA exhibited antibacterial activity. Additional biological experiments showed that SC and SCOA had relatively high activity for the reversal of $\mathrm{H}_{2} \mathrm{O}_{2}$-induced cell death in 3T3-L1 adipocytes, and SCOA showed the highest effect on attenuation of lipid accumulation in 3T3-L1 adipocytes. Among these LMW fucoidans, SCOA showed antibacterial activity and had a high fucose content, high sulfate content, high activity for the reversal of $\mathrm{H}_{2} \mathrm{O}_{2}$-induced cell death, and a marked effect on attenuation of lipid accumulation, and we thus recommend it as a natural and safe antibacterial and anti-adipogenic agent for food, cosmetic, and nutraceutical applications. Further in vivo anti-adipogenic studies, especially on SCOA, are required.

Acknowledgments: This work was supported by a grant provided by the Ministry of Science and Technology (Grant No. MOST 106-2320-B-022-001), Taiwan, awarded to Chun-Yung Huang.

Author Contributions: Chun-Yung Huang and Chia-Hsin Lee conceived and designed the experiments; Chia-Hsin Lee and Chia-Hung Kuo performed the experiments; Chun-Yung Huang and Chia-Hung Kuo analyzed the data; Chun-Yung Huang contributed reagents/materials/analysis tools; and Chun-Yung Huang wrote the paper.

Conflicts of Interest: The authors declare no conflict of interest.

\section{References}

1. Wawruch, M.; Bozekova, L.; Krcmery, S.; Kriska, M. Risks of antibiotic treatment. Bratisl. Lek. Listy 2002, 103, 270-275. [PubMed]

2. Abdullah, A.S.H.; Mirghani, M.E.S.; Jamal, P. Antibacterial activity of malaysian mango kernel. Afr. J. Biotechnol. 2011, 10, 18739-18748.

3. Roberts, C.K.; Sindhu, K.K. Oxidative stress and metabolic syndrome. Life Sci. 2009, 84, 705-712. [CrossRef] [PubMed]

4. Wang, J.; Zhang, Q.B.; Zhang, Z.S.; Song, H.F.; Li, P.C. Potential antioxidant and anticoagulant capacity of low molecular weight fucoidan fractions extracted from Laminaria japonica. Int. J. Biol. Macromol. 2010, 46, 6-12. [CrossRef] [PubMed]

5. Sallmyr, A.; Fan, J.; Rassool, F.V. Genomic instability in myeloid malignancies: Increased reactive oxygen species (ROS), DNA double strand breaks (DSBs) and error-prone repair. Cancer Lett. 2008, 270, 1-9. [CrossRef] [PubMed]

6. Halliwell, B. Antioxidants in human health and disease. Annu. Rev. Nutr. 1996, 16, 33-50. [CrossRef] [PubMed]

7. Branen, A.L. Toxicology and biochemistry of butylated hydroxyanisole and butylated hydroxytoluene. J. Am. Oil Chem. Soc. 1975, 52, 59-63. [CrossRef] [PubMed]

8. Ito, N.; Fukushima, S.; Haqlwara, A.; Shibata, M.; Ogiso, T. Carcinogenicity of butylated hydroxyanisole in F344 rats234. J. Natl. Cancer Inst. 1983, 70, 343-352. [PubMed]

9. Roh, J.S.; Lee, H.; Woo, S.; Yoon, M.; Kim, J.; Park, S.D.; Shin, S.S.; Yoon, M. Herbal composition Gambigyeongsinhwan (4) from Curcuma longa, Alnus japonica, and Massa Medicata Fermentata inhibits lipid accumulation in 3T3-L1 cells and regulates obesity in Otsuka Long-Evans Tokushima Fatty rats. J. Ethnopharmacol. 2015, 171, 287-294. [PubMed] 
10. Miranda, P.J.; DeFronzo, R.A.; Califf, R.M.; Guyton, J.R. Metabolic syndrome: Definition, pathophysiology, and mechanisms. Am. Heart J. 2005, 149, 33-45. [CrossRef] [PubMed]

11. Liu, J.F.; Ma, Y.; Wang, Y.; Du, Z.Y.; Shen, J.K.; Peng, H.L. Reduction of lipid accumulation in HepG2 cells by luteolin is associated with activation of AMPK and mitigation of oxidative stress. Phytother. Res. 2011, 25, 588-596. [CrossRef] [PubMed]

12. Lee, O.H.; Seo, M.J.; Choi, H.S.; Lee, B.Y. Pycnogenol ${ }^{\circledR}$ inhibits lipid accumulation in 3T3-L1 adipocytes with the modulation of reactive oxygen species (ROS) production associated with antioxidant enzyme responses. Phytother. Res. 2012, 26, 403-411. [CrossRef] [PubMed]

13. Wu, K.C.; Liu, J.; Klaassen, C.D. Role of Nrf2 in preventing ethanol-induced oxidative stress and lipid accumulation. Toxicol. Appl. Pharmacol. 2012, 262, 321-329. [CrossRef] [PubMed]

14. Ale, M.T.; Maruyama, H.; Tamauchi, H.; Mikkelsen, J.; Meyer, A.S. Fucoidan from Sargassum sp. and Fucus vesiculosus reduces cell viability of lung carcinoma and melanoma cells in vitro and activates natural killer cells in mice in vivo. Int. J. Biol. Macromol. 2011, 49, 331-336. [CrossRef] [PubMed]

15. Ale, M.T.; Mikkelsen, J.D.; Meyer, A.S. Important determinants for fucoidan bioactivity: A critical review of structure-function relations and extraction methods for fucose-containing sulfated polysaccharides from brown seaweeds. Mar. Drugs 2011, 9, 2106-2130. [CrossRef] [PubMed]

16. Garcia-Vaquero, M.; Rajauria, G.; O’Doherty, J.V.; Sweeney, T. Polysaccharides from macroalgae: Recent advances, innovative technologies and challenges in extraction and purification. Food Res. Int. 2017, 99, 1011-1020. [CrossRef] [PubMed]

17. Choi, J.; Kim, H.J. Preparation of low molecular weight fucoidan by gamma-irradiation and its anticancer activity. Carbohydr. Polym. 2013, 97, 358-362. [CrossRef] [PubMed]

18. Huang, C.Y.; Wu, S.J.; Yang, W.N.; Kuan, A.W.; Chen, C.Y. Antioxidant activities of crude extracts of fucoidan extracted from Sargassum glaucescens by a compressional-puffing-hydrothermal extraction process. Food Chem. 2016, 197, 1121-1129. [CrossRef] [PubMed]

19. Yang, W.N.; Chen, P.W.; Huang, C.Y. Compositional characteristics and in vitro valuations of antioxidant and neuroprotective properties of crude extracts of fucoidan prepared from compressional puffing-pretreated Sargassum crassifolium. Mar. Drugs 2017, 15. [CrossRef]

20. Chiang, P.S.; Lee, D.J.; Whiteley, C.G.; Huang, C.Y. Antioxidant phenolic compounds from Pinus morrisconicola using compressional-puffing pretreatment and water-ethanol extraction: Optimization of extraction parameters. J. Taiwan Inst. Chem. Eng. 2017, 70, 7-14. [CrossRef]

21. Chiang, P.S.; Lee, D.J.; Whiteley, C.G.; Huang, C.Y. Extracting antioxidant phenolic compounds from compressionalpuffing pretreated Pinus morrisonicola: Effects of operational parameters, kinetics and characterization. J. Taiwan Inst. Chem. Eng. 2017, 75, 70-76. [CrossRef]

22. Zhang, Z.S.; Wang, X.M.; Mo, X.F.; Qi, H.M. Degradation and the antioxidant activity of polysaccharide from Enteromorpha linza. Carbohydr. Polym. 2013, 92, 2084-2087. [CrossRef] [PubMed]

23. Zhou, J.; Hu, N.; Wu, Y.L.; Pan, Y.J.; Sun, C.R. Preliminary studies on the chemical characterization and antioxidant properties of acidic polysaccharides from Sargassum fusiforme. J. Zhejiang Univ. Sci. B 2008, 9, 721-727. [CrossRef] [PubMed]

24. Tissot, B.; Salpin, J.Y.; Martinez, M.; Gaigeot, M.P.; Daniel, R. Differentiation of the fucoidan sulfated L-fucose isomers constituents by CE-ESIMS and molecular modeling. Carbohydr. Res. 2006, 341, 598-609. [CrossRef] [PubMed]

25. Li, B.; Lu, F.; Wei, X.J.; Zhao, R.X. Fucoidan: Structure and bioactivity. Molecules 2008, 13, 1671-1695. [CrossRef] [PubMed]

26. Hu, M.; Cui, N.; Bo, Z.X.; Xiang, F.X. Structural determinant and its underlying molecular mechanism of STPC2 related to anti-angiogenic activity. Mar. Drugs 2017, 15. [CrossRef] [PubMed]

27. Imbs, T.I.; Skriptsova, A.V.; Zvyagintseva, T.N. Antioxidant activity of fucose-containing sulfated polysaccharides obtained from Fucus evanescens by different extraction methods. J. Appl. Phycol. 2015, 27, 545-553. [CrossRef]

28. Sun, L.; Wang, L.; Li, J.; Liu, H. Characterization and antioxidant activities of degraded polysaccharides from two marine Chrysophyta. Food Chem. 2014, 160, 1-7. [CrossRef] [PubMed]

29. Ananthi, S.; Raghavendran, H.R.B.; Sunil, A.G.; Gayathri, V.; Ramakrishnan, G.; Vasanthi, H.R. In vitro antioxidant and in vivo anti-inflammatory potential of crude polysaccharide from Turbinaria ornata (Marine Brown Alga). Food Chem. Toxicol. 2010, 48, 187-192. [CrossRef] [PubMed] 
30. Peasura, N.; Laohakunjit, N.; Kerdchoechuen, O.; Wanlapa, S. Characteristics and antioxidant of Ulva intestinalis sulphated polysaccharides extracted with different solvents. Int. J. Biol. Macromol. 2015, 81, 912-919. [CrossRef] [PubMed]

31. Zhou, C.S.; Yu, X.J.; Zhang, Y.Z.; He, R.H.; Ma, H.L. Ultrasonic degradation, purification and analysis of structure and antioxidant activity of polysaccharide from Porphyra yezoensis Udea. Carbohydr. Polym. 2012, 87, 2046-2051. [CrossRef]

32. Zhao, T.T.; Zhang, Q.B.; Qi, H.M.; Zhang, H.; Niu, X.Z.; Xu, Z.H.; Li, Z. Degradation of porphyran from Porphyra haitanensis and the antioxidant activities of the degraded porphyrans with different molecular weight. Int. J. Biol. Macromol. 2006, 38, 45-50. [CrossRef] [PubMed]

33. Liu, M.; Liu, Y.X.; Cao, M.J.; Liu, G.M.; Chen, Q.C.; Sun, L.C.; Chen, H.X. Antibacterial activity and mechanisms of depolymerized fucoidans isolated from Laminaria japonica. Carbohydr. Polym. 2017, 172, 294-305. [CrossRef] [PubMed]

34. He, F.; Yang, Y.; Yang, G.; Yu, L.J. Studies on antibacterial activity and antibacterial mechanism of a novel polysaccharide from Streptomyces virginia H03. Food Control 2010, 21, 1257-1262. [CrossRef]

35. Yamashita, S.; Sugita-Konishi, Y.; Shimizu, M. In vitro bacteriostatic effects of dietary polysaccharides. Food Sci. Technol. Res. 2001, 7, 262-264. [CrossRef]

36. Leong, L.P.; Shui, G. An investigation of antioxidant capacity of fruits in Singapore markets. Food Chem. 2002, 76, 69-75. [CrossRef]

37. Jiménez-Escrig, A.; Rincón, M.; Pulido, R.; Saura-Calixto, F. Guava fruit (Psidium guajava L.) as a new source of antioxidant dietary fiber. J. Agric. Food Chem. 2001, 49, 5489-5493. [CrossRef] [PubMed]

38. Green, H.; Kehinde, O. An established preadipose cell line and its differentiation in culture II. Factors affecting the adipose conversion. Cell 1975, 5, 19-27. [CrossRef]

39. Karadeniz, F.; Karagozlu, M.Z.; Pyun, S.Y.; Kim, S.K. Sulfation of chitosan oligomers enhances their anti-adipogenic effect in 3T3-L1 adipocytes. Carbohydr. Polym. 2011, 86, 666-671. [CrossRef]

40. Yoon, S.O.; Kim, M.M.; Park, S.J.; Kim, D.; Chung, J.; Chung, A.S. Selenite suppresses hydrogen peroxide-induced cell apoptosis through inhibition of ASK1/JNK and activation of PI3-K/Akt pathways. FASEB J. 2002, 16, 111-113. [CrossRef] [PubMed]

41. Park, M.K.; Jung, U.; Roh, C. Fucoidan from marine brown algae inhibits lipid accumulation. Mar. Drugs 2011, 9, 1359-1367. [CrossRef] [PubMed]

42. Kim, K.J.; Lee, O.H.; Lee, B.Y. Fucoidan, a sulfated polysaccharide, inhibits adipogenesis through the mitogenactivated protein kinase pathway in 3T3-L1 preadipocytes. Life Sci. 2010, 86, 791-797. [CrossRef] [PubMed]

43. Dubois, M.; Gilles, K.A.; Hamilton, J.K.; Rebers, P.; Smith, F. Colorimetric method for determination of sugars and related substances. Anal. Chem. 1956, 28, 350-356. [CrossRef]

44. Gibbons, M.N. The determination of methylpentoses. Analyst 1955, 80, 268-276. [CrossRef]

45. Filisetti-Cozzi, T.M.; Carpita, N.C. Measurement of uronic acids without interference from neutral sugars. Anal. Biochem. 1991, 197, 157-162. [CrossRef]

46. Bradford, M.M. A rapid and sensitive method for the quantitation of microgram quantities of protein utilizing the principle of protein-dye binding. Anal. Biochem. 1976, 72, 248-254. [CrossRef]

47. Meda, A.; Lamien, C.E.; Romito, M.; Millogo, J.; Nacoulma, O.G. Determination of the total phenolic, flavonoid and proline contents in Burkina Fasan honey, as well as their radical scavenging activity. Food Chem. 2005, 91, 571-577. [CrossRef]

48. Athukorala, Y.; Jung, W.K.; Vasanthan, T.; Jeon, Y.J. An anticoagulative polysaccharide from an enzymatic hydrolysate of Ecklonia cava. Carbohydr. Polym. 2006, 66, 184-191. [CrossRef]

49. Huang, C.Y.; Kuo, J.M.; Wu, S.J.; Tsai, H.T. Isolation and characterization of fish scale collagen from tilapia (Oreochromis sp.) by a novel extrusion-hydro-extraction process. Food Chem. 2016, 190, 997-1006. [CrossRef] [PubMed]

50. Pandey, J.K.; Swarnkar, R.K.; Soumya, K.K.; Dwivedi, P.; Singh, M.K.; Sundaram, S.; Gopal, R. Silver nanoparticles synthesized by pulsed laser ablation: As a potent antibacterial agent for human enteropathogenic Gram-positive and Gram-negative bacterial strains. Appl. Biochem. Biotechnol. 2014, 174, 1021-1031. [CrossRef] [PubMed]

51. Benzie, I.F.F.; Strain, J.J. The ferric reducing ability of plasma (FRAP) as a measure of "Antioxidant Power": The FRAP Assay. Anal. Biochem. 1996, 239, 70-76. [CrossRef] [PubMed] 
52. Maeda, H.; Hosokawa, M.; Sashima, T.; Takahashi, N.; Kawada, T.; Miyashita, K. Fucoxanthin and its metabolite, fucoxanthinol, suppress adipocyte differentiation in 3T3-L1 cells. Int. J. Mol. Med. 2006, 18, 147-152. [CrossRef] [PubMed]

53. Wang, C.Y.; Wu, T.C.; Hsieh, S.L.; Tsai, Y.H.; Yeh, C.W.; Huang, C.Y. Antioxidant activity and growth inhibition of human colon cancer cells by crude and purified fucoidan preparations extracted from Sargassum cristaefolium. J. Food Drug Anal. 2015, 23, 766-777. [CrossRef] [PubMed]

54. Kellogg, J.; Esposito, D.; Grace, M.H.; Komarnytsky, S.; Lila, M.A. Alaskan seaweeds lower inflammation in RAW 264.7 macrophages and decrease lipid accumulation in 3T3-L1 adipocytes. J. Funct. Foods 2015, 15, 396-407. [CrossRef]

(C) 2018 by the authors. Licensee MDPI, Basel, Switzerland. This article is an open access article distributed under the terms and conditions of the Creative Commons Attribution (CC BY) license (http:/ / creativecommons.org/licenses/by/4.0/). 